\title{
Canghe of Fertility Soils on a Background of Changes of a Climate
}

\section{Budnik S.V.}

The central geophysical observatory it. Boris Sreznevskogo, Kiev, Ukraine

\author{
*Correspondence author \\ Budnik S.V \\ The central geophysical observatory it \\ Boris Sreznevskogo \\ Kiev \\ Ukraine
}

Submitted : 27 Sept 2020 ; Published : 1 Dec 2020

\begin{abstract}
In work the reasons of reduction of stocks rymyca in soils agrolandscapes are considered and ways of more rational use of stocks of organic chemistry on a background of modern consequences of change of a climate are outlined.
\end{abstract}

Keywords: climate, humus, soils, humidifying of territory, the organization of territory

\section{Introduction}

In nature, there are known to be stable biogeochemical cycles of matter and energy that developed over the centuries the period of operation of biogeosystem $[5,8,9]$. Human activity leads to their restructuring, violates the balance of the cycles, withdrawal or supply of the individual components of the cycle. In agrocenoses is the removal of the commodity products and inputs of substances and energy in the form of fertilizers, agrotechnical methods, etc.

\section{Methods and Materials}

Research of the reasons of change of the maintenance humus in soils was spent on the basis of the analysis of numerous scientific researches in various areas of sciences about the Lands and the natures, and also materials of the state statistical service and hydrometeorological service.

\section{Results}

As you know, between the natural ecosystems and agroecosystems there are a number of differences and features. Natural ecosystems are complex systems with a large number of types, characterized by a persistent dynamic equilibrium achieved by self-regulation, the productivity of such a system is determined by the characteristics of opportunistic organisms, taking part in the cycle of matter. Here the cycle of matter close to the lock, the element input with precipitation and litter is almost equal to the biological absorption of elements by plants. The closed loop due to the presence of biological barriers of green and sphagnum moss, preventing the removal of the scarce element supply and surface water runoff outside ecosystem [2]. Primary production here is mainly used by animals and takes part in the circulation of substances, the consumption occur simultaneously with production. As you know, between the natural ecosystems and agro-ecosystems there are a number of differences and features. Natural ecosystems are complex systems with a large number of types, characterized by a persistent dynamic equilibrium achieved by self-regulation, the productivity of such a system is determined by the characteristics of opportunistic organisms, taking part in the cycle of matter. Here the cycle of matter close to the lock, the element input with precipitation and litter is almost equal to the biological absorption of elements by plants. The closed loop due to the presence of biological barriers of green and sphagnum moss, preventing the removal of the scarce element supply and surface water runoff outside ecosystem [9]. Primary production here is mainly used by animals and takes part in the circulation of substances, the consumption occur simultaneously with production.

The fundamental differences between natural ecosystems and agrocenoses are as follows:

1. agricultural landscapes are secondary transformed human units of the biosphere;

2. it also simplified the system with a predominance of populations of the same species of plants and animals;

3. this is not a sustainable system, characterized by the variability of the structure of the biomass;

4. productivity is defined in economic activities and depends on the economic and technical capabilities of the company;

5. high productivity here develops for a short time, consumption and expenditure does not take place simultaneously; 
6. the intensity of use of soil is much lower in arable soil with about $35-40 \%$ of the warm period, and on the black pair more left without use for production and accordingly do not form an additional phytomass;

7. in crops is no layering, the plant density is often less possible;

8. inputs of substances and energy of a man (tillage, fertilizer application, and land reclamation activities, plant protection, etc.);

9. the nutrient cycle is characterized by more pronounced is not a closed loop in comparison with the natural cenosis, which is due to the imbalance of income and removal of substances; the formation of reserves of insoluble compounds in the interaction of fertilizers with soil which leads to low utilization of nutrients from fertilizers; the agricultural systems greatly increase the removal of substances with waters of surface runoff, especially in the development of erosion that is associated with the lack of biological barriers. The variation of quantities of matter flows in agricultural systems is very large, since they depend on the productivity of agroecosystems, the level of culturenet soil and application of fertilizers, etc.

The comparison shows that the functioning of natural ecosystems, the organization in them of the trophic relations in many criteria significantly superior to agro-ecosystems established and regulated by man. For these reasons, in the USSR, in contrast to natural ecosystems soil productivity does not match their fertility and the replenishment of organic matter on principle: how many made from crops, so we need to return to the soil does not compensate for loss of humus, it just leaves the system in its reorganization under less intensive use.
According to [9] a direct relationship between the total quantities of heat and moisture, on the one hand and productivity of green biomass on the other is not observed. However, the richness of the soil is not an indicator of increase of phytomass in zonal mode. In the zonal spectrum of the variability of this indicator is observed, at first glance, a paradox: the more fertile the soil, the lower the productivity of the phytocenosis [5]. The highest rates of increase of biomass is observed on relatively poor soils, but in terms of greatest potential productive regime of solar radiation and humidity, that is in tropical rain forests. As the reduction of water and heat balance of soil fertility naturally rises, and the phytomass decreases [5].

Causes of dehumification soils currently are:

1. low projective cover vegetable cover agriculture and nonuniform distribution over time;

2. the cultivation of plants with lower ash content and low content and, consequently, the consumption of nutrients from soil (in comparison with weeds, and perennial grasses), i.e. the efficiency of humification on their crop residues is lower than in conventional ecosystems;

3. a change in the balance of heat and moisture under the influence of climate change on the planet [1, 2 ets] (fig.1), which creates more favorable conditions for the withdrawal of organic substances.

Changes of a climate in territory of Ukraine are shown in growth of temperature of air, quantity of atmospheric precipitation and evaporations, both from a water table, and from soil (fig.1). On fig. 1 a number of schedules of characteristics of a climate describing change on meteorological stations Sarny and a runoff of water in the river Sluch at the city of Sarny, however similar to the tendency is resulted are characteristic and for other meteorological stations of Ukraine.

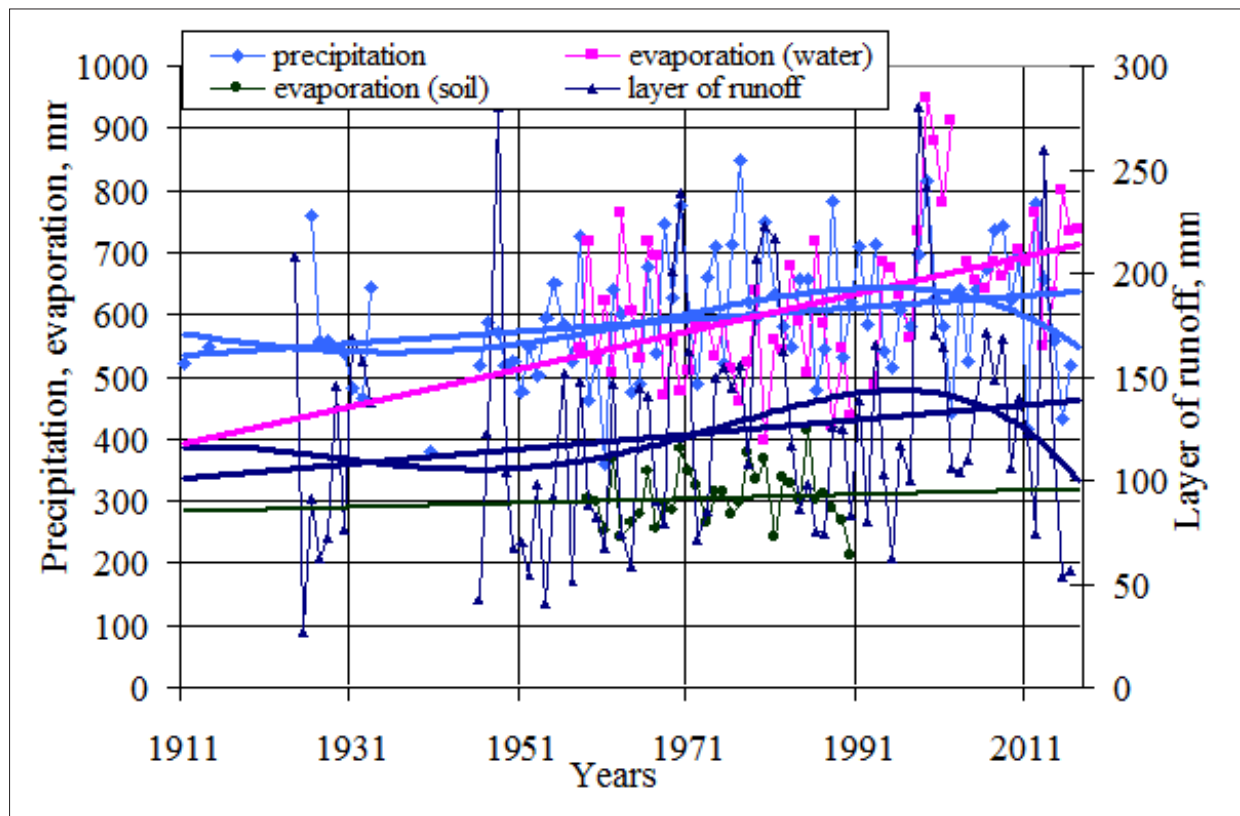

Figure 1: Dynamics in time of precipitation, evaporations from a surface of ground on meteorological station Sarny and a runoff of water the river Sluch - c. Sarny 
The latter explains much of the current paradoxical trend of increasing yields of agricultural crops in Ukraine on the background of reduction of stocks of humus and reduction of fertilizer application (fig.2, 3).

The analysis of materials of the statistical reporting of Gosstatistical of Ukraine shows, that last 16 years growth of productivity of long-term grasses in all territory of Ukraine (рис.2) is observed, growth of temperature of air and atmospheric precipitation is simultaneously observed. The greatest of productivity of long-term grasses on hay are observed in Vinnitsa, Zhitomir, Cherkassk areas.

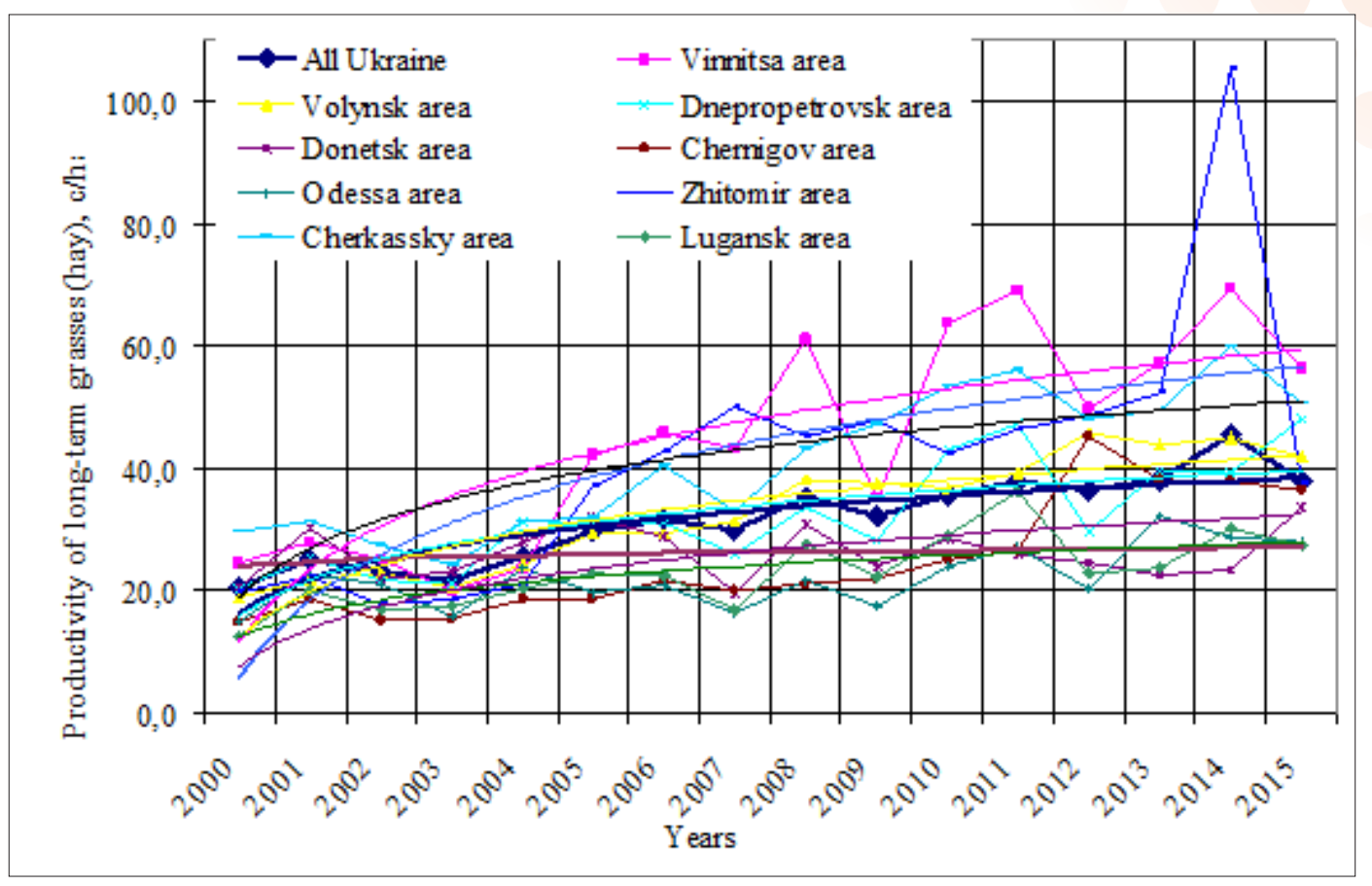

Figure.2: Dynamics productivity long-term grasses (hay) for 2000-2015 as a whole across Ukraine and on separate areas

The greatest communication productivity of long-term grasses shows with superficial evaporation (evaporation from a surface of waters and soils) and presence sour soils.

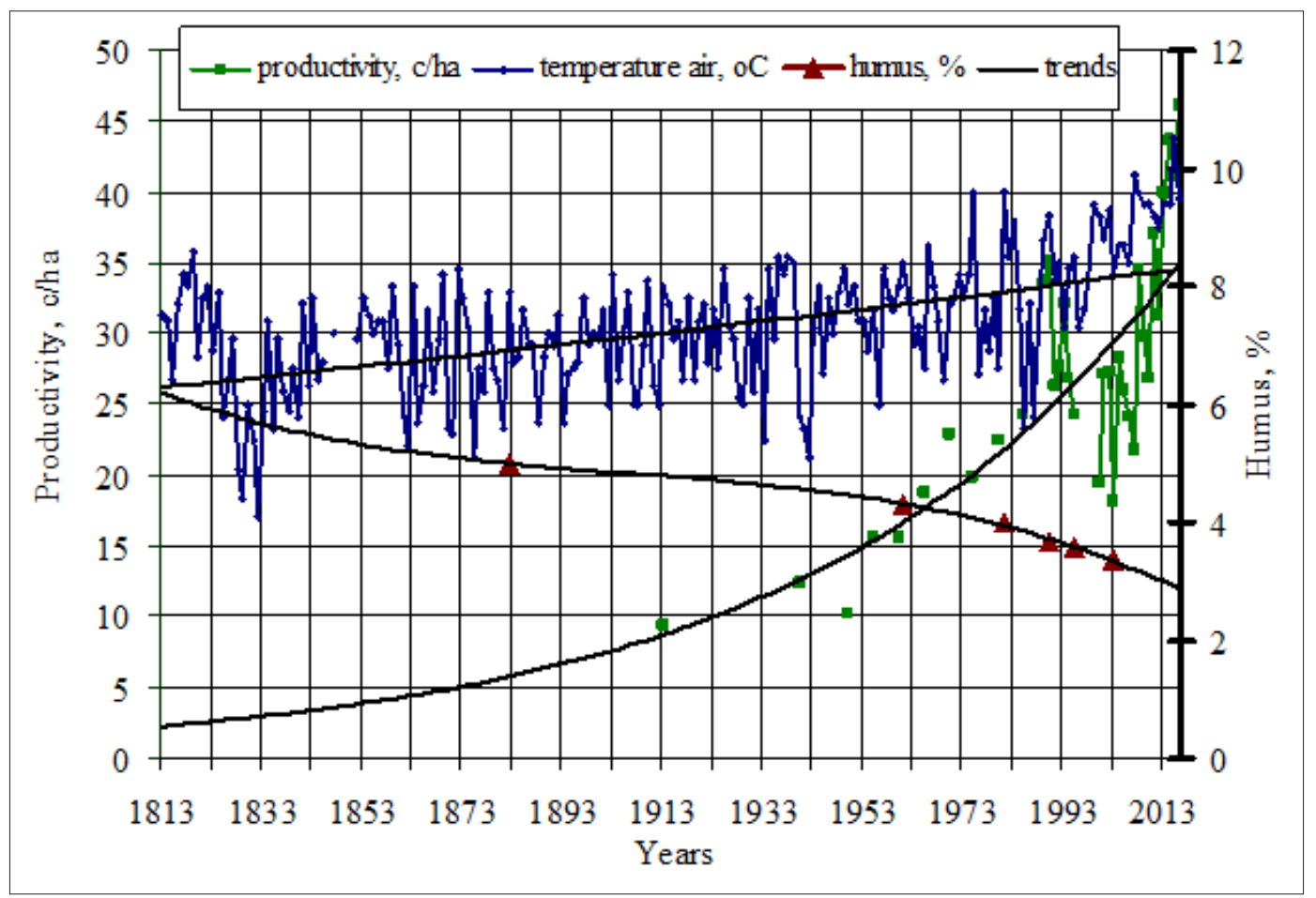

Figure.3: The change in air temperature (meteorological station in Kiev), grain yield and content of humus (Poltava region) in time (according to statistical reports) 


\section{Conclusions}

To ensure a more rational use of soil fertility, prevention of unproductive losses of nutrients from soils due to their more intensive removal in the current hydrothermal conditions, it is necessary to revise technological standards of cultivation of agricultural crops, to find a more rational crop rotations, more use of the possibilities of land reclamation, etc. One of the main limiting factors here is the lack of predictability and informativeness of long-term weather forecasts (for a year or more).

For environmentally sustainable natural resource management is recommended as a backbone unit to make use of basin landscape structure [3 and others], since flows of matter and energy flowing in it is convenient to take into account. Here, these flows acquire specific quantitative indicators are easily interpretable. Any economic events or climatic fluctuations, one way or another, affect them. However, not only land use affects rivers and their watersheds, but also the condition of water objects (their water content, characteristics of the watershed) also affect land use. Thus, the yield of agricultural crops shows a connection with the catchments area, its average height, forest square. Water flow and sediment transport also affects crop yields. That is, polluting the watersheds of rivers, withdrawing a considerable part of their flow, we are not only destroying the rivers as landscape elements, but also driven to degradation tracts of arable land and lose part of the production.

Observed changes of a climate on globe cause redistribution of heat and a moisture on territory that leads places excessive dries up the soils, and places to sudden strong flooding [1-3 etc.] etc. It compels farmers to reconsider technologies of cultivation of agricultural crops, builders - to change building norms of durability and durability of designs and in general approaches to a lay-out of the occupied places, etc. [1, 4, 6, 7 etc.] In this respect the action, capable to settle distribution of a moisture and heat on territory the existential organization of territory of land tenure or settlement $[4,8,11,14$, etc.] can act. Earlier more often about the existential organization of territory it was spoken as about active means in reduction of erosive processes and rational planning of managing [4, 6, 7 etc.]. These researches show effective mechanisms of regulation обводнения to territory, creations of a favorable microclimate, preservation of fertility of soils, etc. [1, 2, 4-6 etc.]. At flooding the special organization of territory does not allow water to flow down quickly in downturn of a relief and it reduces peak of a high water, i.e. extension a freshet wave, that in itself reduces a flood damage, the water distributed on a reservoir sates the top layer soils-grounds and provides vegetation with a necessary moisture, in agrarian landscapes we promote a crop, and in settlements - a favorable microclimate from the wood landings, reducing heating asphalt - concrete designs and coverings.

Research and accounting practice in the agricultural production system-forming functions of agricultural landscapes will create preconditions for increase of efficiency of use of agro- climatic potential of agricultural landscapes to reduce the risk of loss or underproduction of agricultural products, to maintain soil fertility, prevent the loss of rivers as landscape elements, conduct shaping the spatial distribution of crop rotations taking into account the dynamics of humidity of the territory.

\section{References}

1. Bates B C, Z W Kundzewicz, S Wu, J P Palutikof (2008) Eds. Climate Change and Water. Technical Paper of the Intergovernmental Panel on Climate Change, IPCC Secretariat, Geneva $210 \mathrm{pp}$.

2. Stockker TF, D Qin, J-C Plattner, M Tignor, SK Allen, J Boschung, A Nauels, Y Xia, W Becks, P. M. Midgley (2013) (editors).Climate change. Physical scientific basis. Summary for Policymakers IPCC Working Group I Report Technical Summary Working Group I Contribution to the Fifth Assessment Report of the Intergovernmental Panel on Climate Change Cambridge University Press, Cambridge, United Kingdom, and New York, USA. IPCC: 222 p. (on russion)

3. M Svoboda, B A Fuchs (2016) Handbook of Drought Indicators and Indices. Integrated Drought Management Programme (IDMP), Integrated Drought Management Tools and Guidelines Series 2. / Editors. - Geneva: World Meteorological Organization (WMO) and Global Water Partnership (GWP): 60 p.

4. Land husbandry - components and strategy./ By Eric Roose. 70 FAO soils bulletin. Rome. 1996. 302 p.

5. Lisetskiy F.N (2000) Spatio-temporal organization of agricultural landscapes. - Belgorod: Publishing house Bel. state University 304 p. (on russion)

6. OG Tararico, MG Lobasa K (1998) Standards of soil protection contour-reclamation systems of agriculture. For order 158 p. (on ukrainian)

7. M VO Agropromizdat (1990) Design and creation of systems of anti-erosion measures on catchments (recommendations) 32s. (on russion)

8. Titlyanova A.A (1989) On the modes of biological circulation in terrestrial biogeocenoses. // Soil Science No. 6. P.71-80. (on russion)

9. Cherepnin V.L (1999) Phytomass of the Earth's land and climate.-Krasnoyarsk.129 s. (on russion)
Copyright: (C2020 Budnik S.V. This is an open-access article distributed under the terms of the Creative Commons Attribution License, which permits unrestricted use, distribution, and reproduction in anymedium, provided the original author and source are credited. 